studies are said to have appeared in 1956 , and there are four mistakes in the German title of this single work), and third, and most irritating, the text and references do not always agree (there are differences in dates and names, and some references do not appear at all). These are all minor points, but as they are indicative of careless compilation and proof reading they undermine one's confidence in the book. The book is well illustrated, many of the photomicrographs being in colour, but several of the figures are duplicated.

This book will be of interest to those working on arterial disease, but one feels that the author should either have expanded his review chapters and made them more critical, or compressed them into a coherent whole and made the main body of his work relate to his own personal field of vessel wall tissue culture.

\section{Some Aspects of Internal Irradiation}

Edited by T. F. Dougherty and others. Proceedings of a Symposium held in Heber, Utah, in 1961 . Pp. xiii +529 , illustrated. Oxford, London, New York, Paris: Pergamon Press. 1963. $£ 5$.

In the preface, Thomas F. Dougherty, one of the Editors, points out that there are few reviews concerning pathological changes induced by internal irradiation, and the aim of this Symposium was to bring those with interest in this field together.

As might be expected from so many distinguished contributors, the standard of the individual papers was very high. When published in a single volume, together with details of the subsequent discussion which took place, the result is a most valuable book. This should not only be of interest to Radiologists, Medical Physicists and Radiotherapists, but to cancer research workers, Pathologists and many general Physicians.

The book is well indexed and in my opinion should be available as a standard book of reference in every relevant department.

\section{Tumur Viruses of Murine Origin-Ciba Foundation Symposium}

Edited by G. E. W. Wolstenholme and M. O'Connor. Pp. xiii +441 , with 72 illustrations. London: J. \& A. Churchill. 1962. 6os.

This symposium, consisting of seventeen papers contributed and discussed by leading researchers in the field of murine tumour viruses, was held in Perugia, Italy in June r96r. It served to bring up to date and to concentrate a vast amount of knowledge in this rapidly advancing field.

W. Bernard and Nicole Granboulan describe the electron microscopic morphology of oncogenic and nononcogenic murine viruses.

Three papers are devoted to the mouse mammary tumour agent of Bittner. More than one-third of the symposium deals with leukemogenesis in the mouse. Ludwik Gross, who in r95 I demonstrated that spontaneous murine leukemia could be transmitted by cellfree extracts to newborn mice of a low-leukemic strain, reviews the origin, biological and pathogenic properties of the Gross 'passage A' virus. In AKR mice, according to D. Metcalf, an abnormoral adrenal-thymic homeostatic regulation results in an increased level of proliferative activity in the thymic cortex, thus resulting in a favourable environment for the proliferation of the Gross virus. J. F. A. P. Miller, however, after experiments involving thymectomized mice, suggests that the thymus provides the necessary environment wherein the lymphocytes in virus-infected hosts can be transformed to fully autonomic leukemic cells. Miller's theory is based on the fact that mice thymectomized at birth do not develop leukemia although the virus is present in the tissues of the animal. Such an animal, if give thymus graft from a susceptible newborn animal ofill develop leukemia in the graft.

Other papers cover the polyoma virus. The discussiọns following each paper, as well as the general discus at the end of the symposium, are both stimulating and informative, and add immeasurably to the value of this volume.

\section{Fluid and Electrolytes in Practice}

Harry Stadland, M.D. Third edition. Pp. xv\{ +

239. London: Pitman Medical. Philadelp J. B. Lippincott. I963. $63 s$.

This book is aimed to 'facilitate the practical application of disorders of fluid and electrolyte metabolism for the student and practising physician'. In this it is largyly successful, for this notoriously difficult subjecto is presented here in a relatively simple and straightformard manner. The type is large and clear, there are frequent subheadings and the absence of references in the all help to make it an easily readable book. There is a good index and a useful, mainly American, bibliograpty at the end, but the original source of controversial stafements is not always evident, so that the book may dot be so useful for the more knowledgeable.

The first part is concerned with general principles ond application to surgery, the second half being restricted to a few special situations, including a valuable chapter on pædiatric fluid balance. There is some discordance in presentation in this respect, for several other subjects could have been usefully included in the second part, such as a chapter on respiratory failure and another on corticosteroids, and pituitary and adrenal disorders receive rather scant and scattered attention.

Although there are several views with which on dôfes not agree, the subject matter is mainly accurate, ortfotox and up to date. For instance, it is agreeable to find that the routine prophylactic administration of potasstwm is recommended for all patients, with normal rēal function, having prolonged intravenous therapy. क् क्रe chapter on surgical management gives a clear accopint of the physiological response to trauma or operation and sound practical advice. However, it might heve been more helpful if there had been further discussion on the too frequent post-operative electrolyte complications which lead to so much confusion and difficult in practice, even though these usually originate from lack of knowledge of the fundamental principles alreg outlined.

The book can be strongly recommended to unerand postgraduates because of the clear presentation of important principles, but it is doubtful whethes it will be so helpful to the practising physician as the preface would suggest.

\section{Medical Embryology; Human Development Normal and Abnormal \\ J. Langman. Pp. 335, illustrated. \\ Bailliere, Tindall \& Cox. 1963. 7os. \\ Londỡ :}

The author of this book, who is the Professofof Anatomy at McGill University, Monrreal, has set Qut to produce a concise textbook of embryology for cthe medical student. One must immediately say that the attempt has been successful. Considerable attention is paid to clinical features of importance and a chapteras been devoted to the atiology of congenital deferts. Throughout the text particular emphasis is placed fon human development. The book is most pleasantly produced and the text is easy to read. A particular word of praise must go to the illustrations; these are extrenty clear, of high artistic merit and add considerably to 9 he value and beauty of the book. 